\title{
Phosphonic anchoring groups in organic dyes for solid-state solar cells
}

Antonio Abate, ${ }^{* \dagger}$ a,b Raquel Pérez Tejada, ${ }^{c}$ Konrad Wojciechowski, ${ }^{\text {a }}$ Jamie M. Foster, ${ }^{\text {d }}$ Aditya

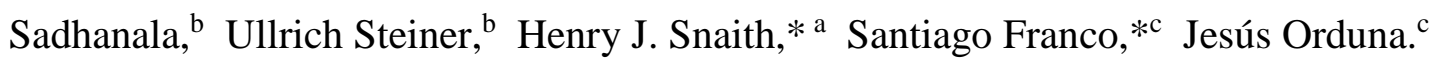

${ }^{a}$ Department of Physics, University of Oxford, Oxford, Parks Road,OX1 3PU, U.K.

${ }^{b}$ Cavendish Laboratory, Department of Physics, University of Cambridge, $19 \mathrm{JJ}$ Thomson Ave, Cambridge, CB3 OHE, UK

cInstituto de Ciencia Materiales de Aragón, Departamento Química Orgánica, Universidad de ZaragozaCSIC, Spain

${ }^{d}$ Department of Mathematics \& Statistics, McMaster University, Hamilton, Ontario, L8S 4K1, Canada.

* Corresponding authors: AA antonioabate83@gmail.com, HJS h.snaith1@physics.ox.ac.uk, SF sfranco@unizar.es.

† Present address: Department of Chemistry and Chemical Engineering, Swiss Federal Institute of Technology, Station 6, CH-1015 Lausanne, Switzerland

KEYWORDS. Organic dyes, solid-state dye-sensitized solar cells, phosphonic acid anchoring group, photovoltaic, solar cells 


\begin{abstract}
We report the synthesis and the optoelectronic characterization of three new $4 H$-pyran-4-ylidene and thiazole derivatives (pyt) as metal-free organic dyes for solid-state dye-sensitized solar cells (DSSCs). We investigate the performance and the long-term stability of devices employing pyt dyes functionalized with carboxylic and phosphonic acids as $\mathrm{TiO}_{2}$ anchoring groups. In contrast to reports on liquid electrolyte DSSCs, we show that solid-state DSSCs prepared with phosphoric pyt derivatives can achieve similar power conversion efficiency to their carboxyl analogues. We make use of Mott-Schottky analysis and equivalent circuit models to demonstrate that phosphonic group induces a significantly increase in built-in voltage at the $\mathrm{TiO}_{2}$-hole transporter interface, which results in higher open circuit voltage.
\end{abstract}




\section{INTRODUCTION}

The growing energy demand and the necessity of sustainable energy generation will require electric power harvested from renewable energy sources. ${ }^{1,2}$ The production of sustainable energy can either be concentrated where the renewable resource is most abundant or it can be directly produced where needed. The latter is preferred to avoid distribution losses and costs. ${ }^{3}$ Solar energy is the most abundant renewable sources for distributed energy production, in particular because a number of different photovoltaic technologies are available that can match diverse requirements of energy generation. ${ }^{4}$ The sun light to electric power conversion efficiency (PCE) and the cost per Watt are the figures of merit commonly used to characterize the performance of photovoltaic technologies. Among others, the recent organic-inorganic perovskite solar cells seems particularly promising to deliver high PCE at low cost. ${ }^{5}$ They still suffer however from insufficient lifetimes. Also, depending on the particular application, other criteria could be decisive when selecting the most appropriate technology. For example, differently coloured solar cells are commercially valuable for buildings, automotive applications and portable device integration. ${ }^{6,7}$ In these applications, dye-sensitized solar cells (DSSCs) are the most flexible photovoltaic technology, offering a potentially infinite choice of colours with reasonable PCE and at low cost. ${ }^{8-11}$

A typical DSSC consists of an electron-transporting layer of dye-sensitized $\mathrm{TiO}_{2}$ nanoparticles, which are infiltrated with a redox electrolyte. They have been widely investigated over the last 20 years, since the first successful demonstration by O’Regan and Grätzel. ${ }^{12}$ Beyond the effort to improve the PCE, much of the research activity has been focused on their long-term operational stability, which is now at a stage that allows the commercialisation of liquid electrolyte DSSCs. ${ }^{13-16}$ Several studies have indicated that dye desorption from the $\mathrm{TiO}_{2}$ surface is one of the primary reasons of performance degradation. ${ }^{16}$ Carboxylic acids are the most commonly used anchoring group to attach dye molecules to the $\mathrm{TiO}_{2}$ surface, but they can be easily hydrolysed in presence of water or alkaline conditions, causing their desorption, thus compromising the device operation. Among several alternatives to carboxylic acids, ${ }^{17-20}$ phosphonic acids have been proposed as $\mathrm{TiO}_{2}$ anchoring group to improve device stability. ${ }^{21-23}$ Indeed, a number of reports showed that phosphonic acids tend to bind more strongly to metal oxide surfaces than carboxylic acids. ${ }^{24-}$ 27 These reports predicted however a reduced electron injection efficiency from the photoexcited dye into the $\mathrm{TiO}_{2}$ conduction band when phosphonic acid anchoring groups are used, potential leading to a higher charge recombination. These theoretical predictions have recently been confirmed in a systematic study of liquid electrolyte DSSCs by Brennan and co-workers. ${ }^{21}$ They showed reduction in PCE by a factor of two for metal-complex based dye functionalized with a phosphonic rather than with a carboxylic anchoring group. Several other publications also reported the use of phosphonic acid as a dye anchoring group in liquid electrolyte DSSCs, ${ }^{28-31}$ but a systematic comparison between carboxylic and phosphonic groups on 
device PCE and long-term stability is missing. In particular, metal-free organic dyes with phosphonic acid anchoring groups have not been reported. Compared to metal-complexes, metal-free organic dyes often achieve higher molar extinction coefficients, ${ }^{32,33}$ which are particularly important to fully absorb light in devices with short optical path lengths, for example in solid-state DSSCs (ss-DSSCs) ${ }^{34}$ where a number of factors limit thickness of the absorbing layer to less than $3 \mu \mathrm{m}$.

Here, we report the synthesis and the optoelectronic characterization of three new $4 H$-pyran-4-ylidene and thiazole derivatives (pyt) as metal-free organic dyes. We investigate the device performance and the longterm stability of ss-DSSCs employing pyt dyes functionalized with carboxylic or phosphonic acids as $\mathrm{TiO}_{2}$ anchoring groups. We show how the anchoring groups influence the electronic properties of the $\mathrm{TiO}_{2}$ junction and how this impacts on device operation. Finally, we demonstrate that organic dyes employing phosphonic acid anchoring groups achieve a similar PCE as carboxylic acid analogues in ss-DSSCs. 


\section{Synthesis and optoelectronic characterization}<smiles>[R]C(C#N)=Cc1cnc(C=C2C=C(c3ccccc3)OC(c3ccccc3)=C2)s1</smiles>



Figure 1. Molecular structure of the compounds prepared for this study, where $\mathrm{R}$ is a carboxylic acid, pyt$\mathrm{COOH}$, a phosphonic acid, pyt-PO(OH)2, or mono-protected phosphonic acid, pyt-PO(OEt)OH.

Figure 1 shows the molecular structure of the conjugated organic compounds prepared for this study. The molecules consist of the same 4H-pyran-4-ylidene and thiazole unit (pyt), which is linked to 2cyanovinylcarboxylic acid, pyt-COOH, cyanovinylphosphonic acid, pyt- $\mathrm{PO}(\mathrm{OH})_{2}$, and mono-protected cyanovinylphosphonic acid, pyt-PO(OEt)OH. All compounds have been synthesized with a good yield by a three step procedure starting from (2,6-diphenyl-4H-pyran-4-yl)diphenylphosphine oxide. The synthetic protocol includes a Horner reaction, followed by a formylation and a final Knoevenagel condensation. Details on the synthetic methods and the chemical characterization of the final compounds are given in the Experimental Section. 




Figure 2. Calculated molecular orbital distribution of HOMO (left), LUMO (right), relative energy levels, vertical excitation energy at the absorption maximum $(\lambda)$ and adiabatic excitation energy $\left(E_{0-0}\right)$, simulating DMF as solvent at TD-M06-2x/6-311+G(2d,p)//M06-2x/6-31G* level of theory.

Figure 2 shows the distribution of the highest occupied molecular orbital (HOMO) and the lowest unoccupied molecular orbital (LUMO) of pyt-COOH, pyt-PO(OH $)_{2}$ and pyt-PO(OEt)OH, with the 
corresponding energy levels and the excitation energies calculated from DFT, simulating dimethylformamide (DMF) as solvent. In all the compounds, the HOMO is mainly distributed over the 4H-pyran-4-ylidene and in part on the thiazole unit, while the LUMO is mainly located on the thiazole and the cyanovinylcarboxylic or the cyanovinylphosphonic units. With such a molecular orbital distribution, the HOMO-LUMO photoexcitation moves electron density from the $4 \mathrm{H}$-pyran-4-ylidene unit, which acts as an electron donor moiety, towards the cyanovinylcarboxylic or the cyanovinylphosphonic units, which act as electron acceptors. Changing the electron acceptor moiety from a carboxylic to a phosphonic group marginally affects the HOMO, but has a strong impact on the LUMO energy. Indeed, the LUMO energy level of the phosphonic compounds is about $0.1 \mathrm{eV}$ closer to vacuum and consequently the HOMO to LUMO excitation energy is larger than in the carboxylic compound. We note that the level of theory used in this study did not predict any difference between the two phosphonic derivatives, pyt-PO(OEt)OH and pyt- $\mathrm{PO}(\mathrm{OH})_{2}$.

Table 1. Electrochemical and optical parameters.

\begin{tabular}{|l|c|c|c|c|}
\hline & $\begin{array}{c}E_{0-0} \\
(\mathrm{eV})\end{array}$ & $\begin{array}{c}E_{\text {ox }}(\mathrm{V}) \\
\text { vs. NHE }\end{array}$ & $\begin{array}{c}E_{\text {HOMO }} \\
(\mathrm{eV})\end{array}$ & $\begin{array}{c}E_{\mathrm{LUMO}} \\
(\mathrm{eV})\end{array}$ \\
\hline pyt-COOH & 2.28 & 1.01 & -6.01 & -3.73 \\
\hline pyt-PO(OH) & 2.46 & 0.93 & -5.90 & -3.44 \\
\hline pyt-PO(OEt)OH & 2.43 & 0.92 & -5.89 & -3.46 \\
\hline
\end{tabular}

Table 1 lists the main electrochemical and optical parameters as measured by differential pulse voltammetry, UV-Vis light absorption and emission spectra (see SI for details). The zero-zero transition energy $\left(E_{0-0}\right)$ was estimated from the intersection of the absorption and emission spectra (see SI). The HOMO energy ( $\left.Е_{\text {Hомо }}\right)$ was extracted from the oxidation potentials $\left(E_{\mathrm{ox}}\right)$ versus a normal hydrogen electrode (NHE) according to the procedure described by Thompson and co-workers, using the formula $E_{\text {Hомо }}(\mathrm{eV})=-1.4 E_{\mathrm{ox}}(\mathrm{V})-4.6{ }^{32}$ The LUMO energy was extracted using the formula $E_{\mathrm{LUMO}}=E_{\mathrm{HOMO}}+$ $E_{0-0}$. Nevertheless, both computation and experiments show that replacing carboxylic with phosphonic acid has a minor effect on the HOMO, and, it moves the LUMO energy closer to the vacuum level. As a result $E_{0-0}$ is higher for the phosphonic dyes. Furthermore, experimental data shows that $E_{0-0}$ for $p y t-\mathrm{PO}(\mathrm{OEt}) \mathrm{OH}$ is slightly lower (by less than $0.1 \mathrm{eV}$ ) than for pyt- $\mathrm{PO}(\mathrm{OH})_{2}$. 


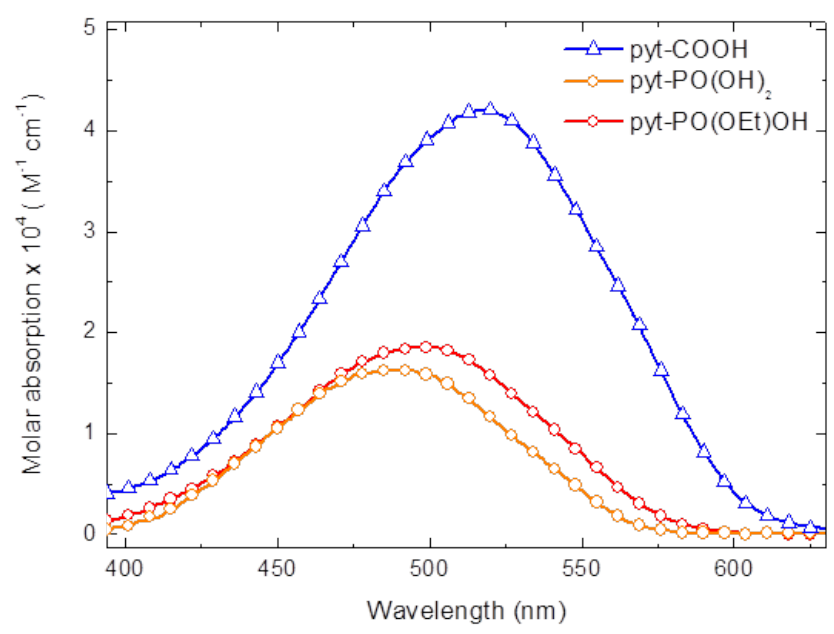

Figure 3. UV-Vis molar absorption spectra for pyt-COOH, pyt-PO(OH $)_{2}$ and pyt-PO(OEt)OH in DMF. Figure 3 shows that all the compounds exhibit relatively broad absorption in the visible region, which matches with the spectra calculated for the intramolecular HOMO-LUMO transition (see SI). Both the phosphonic and the carboxylic compounds have a molar absorption higher than $10^{4} \mathrm{M}^{-1} \mathrm{~cm}^{-1}$ in the 450 $550 \mathrm{~nm}$ spectral region. 


\section{Device performance and long-term stability}

The results of the previous paragraph suggests that conjugated organic compounds based on $4 H$-pyran-4ylidene and thiazole (pyt) can work as effective donor-acceptor organic dyes irrespective of their funtionalisation. The carboxylic acid group of pyt-COOH and the phosphonic acid groups of pyt-PO(OH $)_{2}$ and pyt-PO(OEt)OH can act as an anchoring groups linking the dye molecules to a $\mathrm{TiO}_{2}$ surface. ${ }^{25}{ }^{22}$ Here, the influence of different anchoring groups on device performance and the long-term stability of ss-DSSCs is explored.
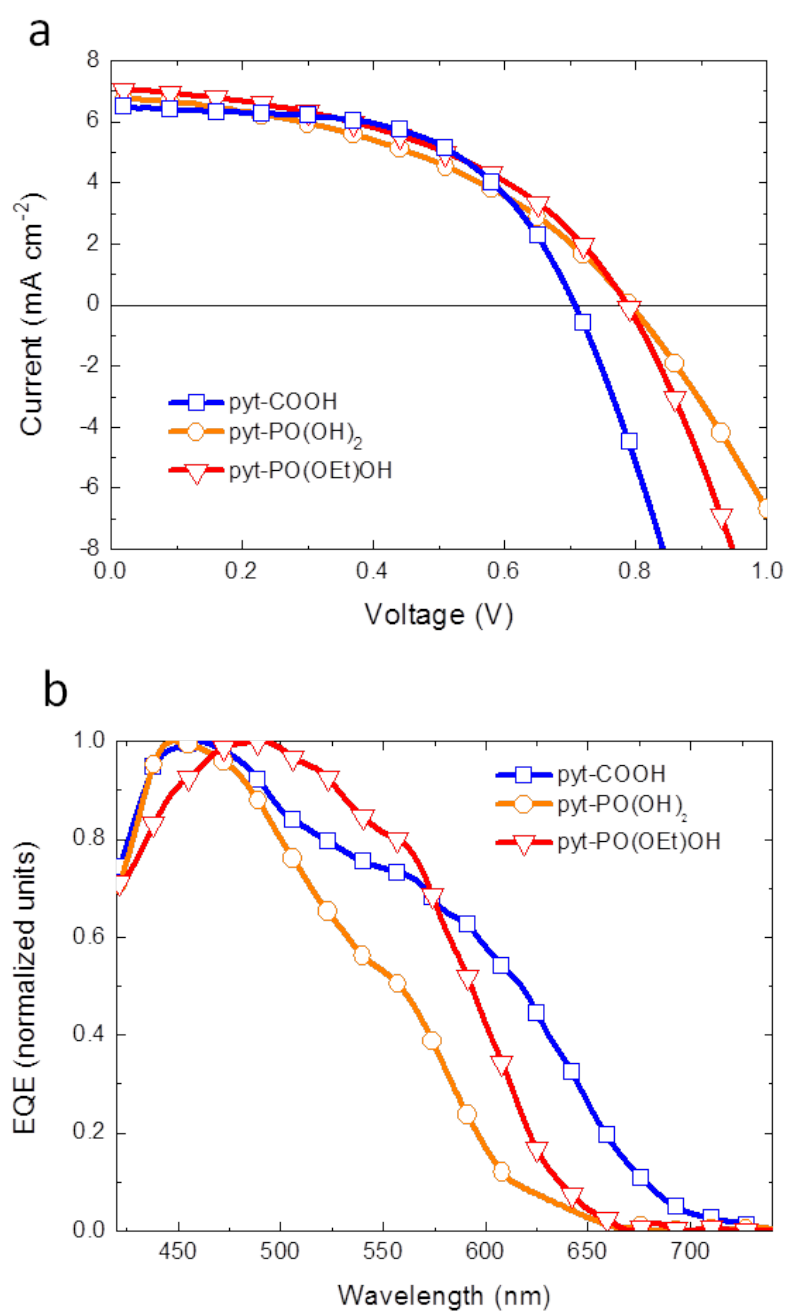

Figure 4. (a) Current-voltage curves under forward bias for devices employing pyt-COOH, pyt- $\mathrm{PO}(\mathrm{OH})_{2}$ and pyt-PO(OEt)OH under AM 1.5 simulated sunlight of $100 \mathrm{~mW} \mathrm{~cm}^{-2}$ equivalent solar irradiance. (b) External quantum efficiency (EQE) spectra normalized at the peak value.

Table 2. Device performance parameters.

\begin{tabular}{|c|c|c|c|c|}
\hline & $J_{\mathrm{sc}}\left(\mathrm{mA} \mathrm{cm} \mathrm{cm}^{-2}\right)$ & PCE (\%) & $V_{\text {oc }}(\mathrm{V})$ & FF \\
\hline pyt-COOH & 6.4 & 2.6 & 0.71 & 0.57 \\
\hline pyt-PO(OH $)_{2}$ & 6.8 & 2.3 & 0.79 & 0.43 \\
\hline pyt-PO(OEt)OH & 7.1 & 2.6 & 0.79 & 0.46 \\
\hline
\end{tabular}


Devices were prepared by sensitizing $1.5 \mu \mathrm{m}$ thick mesoporous $\mathrm{TiO}_{2}$ films with pyt-COOH, pyt$\mathrm{PO}(\mathrm{OH})_{2}$ and pyt-PO(OEt)OH, using 2,2'-7,7'-tetrakis( $N, N$-di-p-methoxyphenylamine)-9,9'spirobifluorene (spiro-OMeTAD) as the hole transporting material (HTM), ${ }^{34}$ adding the commonly used additive combination of lithium bis(trifluoromethanesulfonyl)imide (Li-TFSI) and 4-tert-butylpyridine (TBP). ${ }^{35}$ Figure 4 shows the device current-voltage $(J-V)$ characteristics and external quantum efficiency (EQE) of the best performing devices, with the corresponding performance parameters summarized in Table 2. We note that the PCEs reported in Table 2 were achieved after optimizing the device preparation procedure in several experiments over a period of 6 moths (see Supporting Information). The overall PCE is similar for all three dyes, with pyt- $\mathrm{PO}(\mathrm{OH})_{2}$ slightly lower than pyt-PO(OEt)OH and pyt-COOH. In particular the short circuit currents $\left(J_{\mathrm{sc}}\right)$ are quite similar, since we estimated an error about $0.5 \mathrm{~mA} \mathrm{~cm}^{-2}$. Owing to the lower molar absorption of pyt- $\mathrm{PO}(\mathrm{OH})_{2}$ and pyt- $\mathrm{PO}(\mathrm{OEt}) \mathrm{OH}$, a similar $J_{\mathrm{sc}}$ therefore suggests that the phosphonic anchoring groups provide a more efficient $\mathrm{TiO}_{2}$ sensitization.



Figure 5. Spectral absorption peak as function of the time during $\mathrm{TiO}_{2}$ film sensitization in $0.1 \mathrm{mM}$ dyeing solutions of pyt-COOH, pyt- $\mathrm{PO}(\mathrm{OH})_{2}$ and pyt-PO(OEt)OH in ${ }^{\mathrm{B}} \mathrm{BuOH}: \mathrm{CH}_{3} \mathrm{CN}(1: 1 \mathrm{v}: \mathrm{v})$. The lines are $\mathrm{B}-$ spline interpolations.

To investigate the origin of the relatively high $J_{\mathrm{sc}}$ values of $\mathrm{TiO}_{2}$ sensitised with pyt-PO(OH $)_{2}$ and pyt-PO(OEt)OH, the kinetics of dye loading onto mesoporous $\mathrm{TiO}_{2}$ films was monitored. Figure 5 shows the spectral absorption peak of dyeing solution as function of the time. Note that pyt-PO(OH $)_{2}$ is not stable in ${ }^{\mathrm{t}} \mathrm{BuOH}: \mathrm{CH}_{3} \mathrm{CN}$, showing solution bleaching after only a few hours even in the absence of $\mathrm{TiO}_{2}$ films. This probably is caused by a strong acidic environment induced by the free phosphonic acid group, which 
may be responsible for dye degradation in solution. The data in Figure 5 can therefore not be used to extract information on pyt- $\mathrm{PO}(\mathrm{OH})_{2}$ loading onto $\mathrm{TiO}_{2}$. In contrast, the solutions of pyt-COOH and pyt$\mathrm{PO}(\mathrm{OEt}) \mathrm{OH}$ are stable. The concentration of $\mathrm{PO}(\mathrm{OEt}) \mathrm{OH}$ in solution decreased rapidly during the first 100 minutes and then saturated. Surprisingly, the concentration of pyt-COOH kept decreasing over the entire time monitored window (about 24 hours). This trend may arise either from an extremely slow $\mathrm{TiO}_{2}$ sensitization or from undesired dye aggregation at the $\mathrm{TiO}_{2}$ surface. ${ }^{36,37}$ Since a number of previous studies have shown that the sensitization of thin $\mathrm{TiO}_{2}$ mesoporous films (below $2 \mu \mathrm{m}$ ) with carboxylic organic dyes is completed within 3 hours, ${ }^{38}$ pyt-COOH aggregation onto the first properly chemisorbed layer of molecules is the likely cause for the data in Fig. 5. Notably, PO(OEt)OH does not show any evidence of this type of dye aggregation, which may be a partial cause for the relatively high $J_{\text {sc }}$ despite a molar absorption which is lower than that of pyt-COOH. ${ }^{36,37}$ 


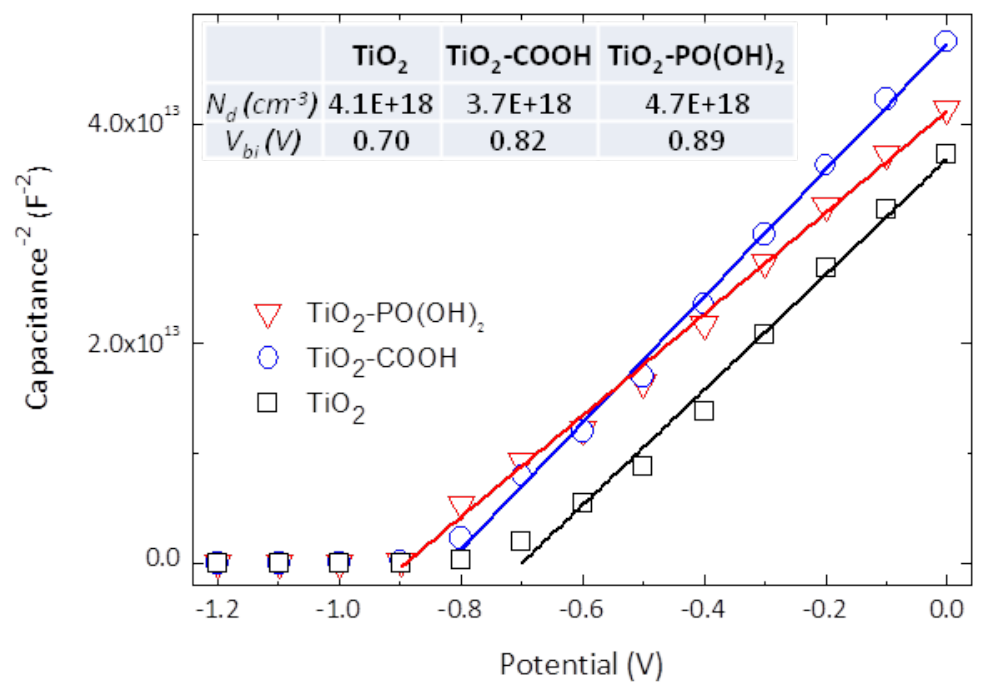

Figure 6. Mott-Schottky plot for p-n junctions between spiro-OMeTAD (p-type material) and $\mathrm{TiO}_{2}(\mathrm{n}-$ type material) without dye sensitization. Benzoic and phenylphosphonic acid were used to mimic the effect of the $\mathrm{COOH}$ and $\mathrm{PO}(\mathrm{OH})_{2}$ anchoring groups on the $\mathrm{TiO}_{2}$. The table lists the doping density $\left(N_{\mathrm{d}}\right)$ and the built-in voltage $\left(V_{\mathrm{bi}}\right)$ extracted from the linear fits.

Table 2 shows that the device open circuit voltage $\left(V_{\text {oc }}\right)$ for the phosphonic dyes is $80 \mathrm{mV}$ higher than the carboxylic analogue. The $V_{\text {ос }}$ is produced by the splitting between the quasi-Fermi level for electrons in the $\mathrm{TiO}_{2}$ and holes in the spiro-OMeTAD. One of the parameters that may affect this energy offset is the doping level of the two semiconductors. ${ }^{15,39,40}$ The doping of the spiro-OMeTAD is mainly controlled by the concentration of Li-TFSI, which has been demonstrated to be an effective p-dopant in presence of oxygen. ${ }^{35}$ For the $\mathrm{TiO}_{2}$, the doping level strongly depends on the concentration of oxygen vacancy defects, which may cause by atomic oxygen diffusing away from the lattice sites reducing $\mathrm{Ti}^{4+}$ ions to $\mathrm{Ti}^{3+}$ at the vacancy sites. $\mathrm{Ti}^{3+}$ ions within the $\mathrm{TiO}_{2}$ lattice have been demonstrated to act as "shallow donors" or n-dopants. ${ }^{41-43}$ The concentration of $\mathrm{Ti}^{3+}$ ions, and thus the doping level, is strongly sensitive to the chemistry at $\mathrm{TiO}_{2}$ surface. ${ }^{44}$

To study the impact of different dye anchoring groups on the doping level of the $\mathrm{TiO}_{2}$, we employed capacitance-voltage measurements, which are a well-established tool to determine the doping density of pn junctions. ${ }^{45}$ Here, we realized a p-n junction with the spiro-OMeTAD (p-type material) in contact with a $\mathrm{TiO}_{2}$ (n-type material) without dye sensitization. To mimic the effect of the dye anchoring groups without introducing additional donor or acceptor levels at the p-n junction caused by redox active dye molecules, benzoic and phenylphosphonic acid were adsorbed onto the surface of mesoporous $\mathrm{TiO}_{2}$. Figure 6 shows a so-called Mott-Schottky plot of inverse capacity squared $C^{-2}$ versus applied voltage, which allows the extraction of the doping density $\left(N_{\mathrm{d}}\right)$ from the slope of a linear fit. ${ }^{45}$ The fitted values of $N_{\mathrm{d}}$ in the table in 
Figure 6 show that the doping levels are rather similar for the bare $\mathrm{TiO}_{2}$ and the $\mathrm{TiO}_{2}$ modified with benzoic acid, $\mathrm{TiO}_{2}-\mathrm{COOH}$. Interestingly, the phenylphosphonic acid, $\mathrm{TiO}_{2}-\mathrm{PO}(\mathrm{OH})_{2}$, slightly enhances $N_{\mathrm{d}}$. This may suggest that phenylphosphonic acid induces a higher number of $\mathrm{Ti}^{3+}$ sites or oxygen vacancies at the $\mathrm{TiO}_{2}$ surface.

The Mott-Schottky plot in Figure 6 also allows to extract the built-in voltage $\left(V_{\mathrm{bi}}\right)$, which is related to the potential difference across the junction in thermal equilibrium. ${ }^{45}$ The $V_{\mathrm{bi}}$ values in Figure 6 show a clear increase from bare to $\mathrm{COOH}$ to $\mathrm{PO}(\mathrm{OH})_{2}$ modified $\mathrm{TiO}_{2}$. In particular, $V_{\text {bi }}$ of $\mathrm{TiO}_{2}-\mathrm{PO}(\mathrm{OH})_{2}$ is $70 \mathrm{mV}$ higher than $\mathrm{TiO}_{2}-\mathrm{COOH}$, which is in good agreement with the $80 \mathrm{mV}$ increase in $V_{\text {oc }}$ found in ss-DSSCs employing the phosphonic anchoring group (see Table 2). 


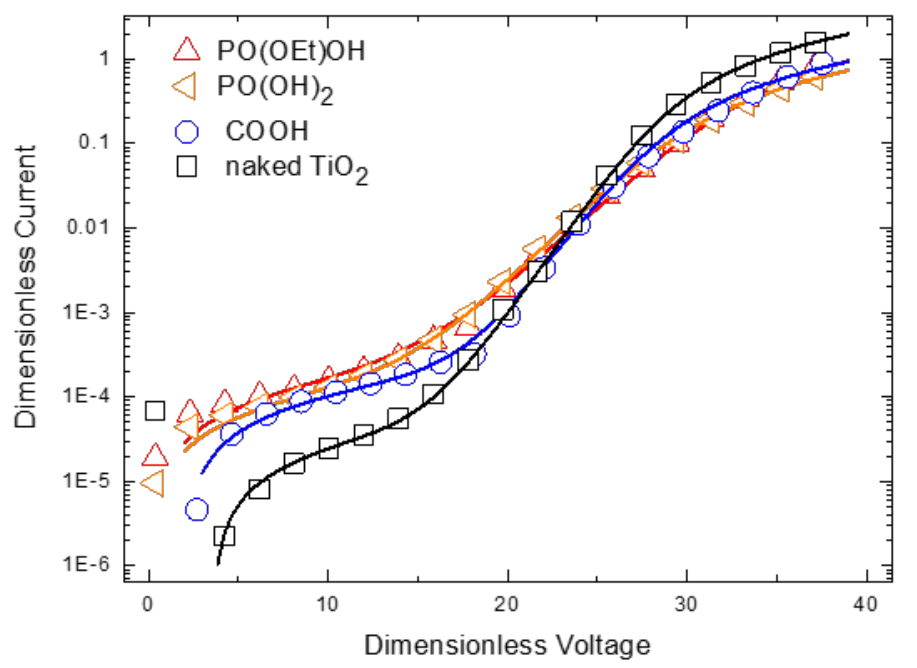

Figure 7. Dimensionless current-voltage curves in the dark for devices employing pyt-COOH, pyt$\mathrm{PO}(\mathrm{OH})_{2}$ and pyt-PO(OEt)OH and without any $\mathrm{TiO}_{2}$ sensitization (naked $\left.\mathrm{TiO}_{2}\right)$. Experimental data (symbols) were fitted with the Shockley equivalent circuit of equation (1) (lines). The dimensionless voltage is measured in units of the thermal voltage and the current density is measured in units of $10 \mathrm{~mA} \mathrm{~cm}^{-}$ 2 .

Table 3. Dimensionless fitting parameters: current density $I_{0}$, ideality factor $N$, shunt and series resistances $R_{\text {shunt }}$ and $R_{s}$. To recover these quantities in their dimensional form the current density $I_{0}$ has to be multiplied by $I^{*}$, and the shunt and series resistances have be multiplied by $V_{\mathrm{t}} /\left(I^{*} A\right)$, where $V_{\mathrm{t}}$ is the thermal voltage (measured in Volts), $A$ is the active area of the cell (measured in $\mathrm{cm}^{2}$ ) and $I^{*}$ is $10 \mathrm{~mA} \mathrm{~cm}{ }^{-2}$.

\begin{tabular}{|l|c|c|c|c|}
\hline & $I_{0}$ & $N$ & $R_{\text {shunt }}$ & $R_{\mathrm{s}}$ \\
\hline naked $\mathbf{T i O}_{2}$ & $9.5 \mathrm{E}-10$ & 1.4 & $3 \cdot 10^{5}$ & 4 \\
\hline pyt-COOH & $2.7 \mathrm{E}-10$ & 1.4 & $9 \cdot 10^{4}$ & 8 \\
\hline pyt-PO(OH) & $1.6 \mathrm{E}-7$ & 2.1 & $9 \cdot 10^{4}$ & 9 \\
\hline pyt-PO(OEt)OH & $3.3 \mathrm{E}-7$ & 2.3 & $7 \cdot 10^{4}$ & 5 \\
\hline
\end{tabular}

Figure 7 shows the dimensionless current-voltage curves in the absence of illumination (in the dark) for devices sensitized with pyt-COOH, pyt- $\mathrm{PO}(\mathrm{OH})_{2}$, pyt-PO(OEt)OH and without any $\mathrm{TiO}_{2}$ sensitization (naked $\mathrm{TiO}_{2}$ ). The current-voltage curves of each of these devices can be compared to the prediction by the well-known Shockley equivalent circuit ${ }^{46}$ which consists of (i) a diode and (ii) a shunt resistor $R_{\text {shunt }}$ in parallel, both in series with a second resistor $R_{s}$. Fitting was performed using dimensionless variables because it allows to determine the ideality factor $N$ of the diode. When the dimensionless current density is plotted on a log scale, the gradient of the linear portion of the current voltage curve is $1 / N$. In dimensionless variables, the Shockley equivalent circuit equation is

$I=I_{0}\left[\exp \left(\frac{V-I * R_{S}}{V_{t} N}-1\right)\right]+\frac{V-I R_{S}}{R_{\text {shunt }}}$, 
where $I, I_{0}, V, R_{s}, N$ and $R_{\text {shunt }}$ are all dimensionless. $I$ is the total current density flowing through the circuit, $I_{0}$ is the reverse saturation current density of the diode, and $V$ is the voltage across the device. The details how these dimensionless quantities are related to their dimensional counterparts are given in the caption of Table 3. A fit of equation (1) to the experimental data of devices sensitized with $\mathrm{COOH}, \mathrm{PO}(\mathrm{OH})_{2}$, $\mathrm{PO}(\mathrm{OEt}) \mathrm{OH}$ and the unsensitized device allows to extract the shunt and series resistances, the reverse saturation current density and the ideality factor of the diode. The fitting results are given in Figure 7 and Table 3. The following trends are observed. First, all sensitized devices exhibit a decrease in $R_{\text {shunt }}$ relative to the naked $\mathrm{TiO}_{2}$. A decrease in the shunt resistance is usually attributed to an increase in the "leakage" of current across the p-n junction. ${ }^{47,48}$ It is therefore likely that the introduction of the dyes creates a small number of Ohmic shunting pathways across the interface that increase parasitic leakage. This effect however only impacts the device performance close to short-circuit conditions, and, more importantly, it does not affect the performance of the devices near the maximum power point. Second, a marked increase in the ideality factor of the diode sensitized the phosphonic dyes was observed (in particular $N>2$ ), indicating that these dyes introduce additional interfacial traps that can act as recombination centres. This supports our hypothesis that the phosphonic acid anchoring group induces higher number of oxygen vacancies at the $\mathrm{TiO}_{2}$ surface (see Figure 6). Note that ideality factors larger than 2 are not well described by the Shockley-Read-Hall (SRH) theory, which describes recombination through defects or bimolecular recombination dynamics only. Schenk et al. and Kirkpatrick et al. have developed two different models for charge carrier recombination that take into account not only one mid-gap trap state (which is assumed in SRH), but multiple mid-gap trap states. ${ }^{49,50}$ These models lead to ideality factors larger than 2, supporting our observation. Third, $I_{0}$ is appreciably increased in the phosphonic dye containing cells. Foster and coworkers have shown that the (pseudo-) band gap, (i.e. the energy difference between the HOMO of the donor and LUMO of the acceptor) determines $I_{0}$. While a direct comparison between our experiments and these theoretical results is difficult, our observation (see Figure 6) that the different dyes each have a different effect on the (pseudo-) band gap at least partially explains the different $I_{0}$ values. 


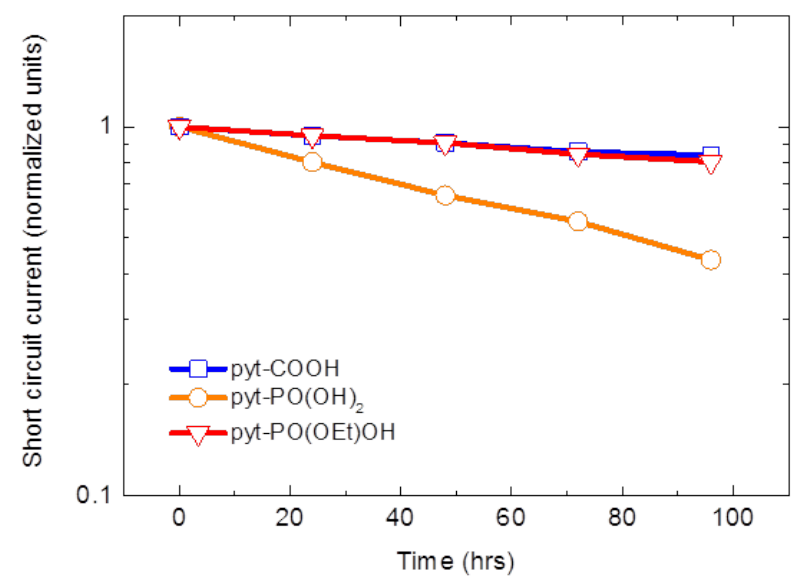

Figure 8. Short circuit current $\left(J_{\mathrm{sc}}\right)$ as function of time for sealed devices under continuous AM 1.5 simulated sunlight illumination of $100 \mathrm{~mW} \mathrm{~cm}^{-2}$ equivalent solar irradiance in open circuit condition at $40^{\circ} \mathrm{C}$.

To study the impact of carboxylic and phosphonic anchoring groups on long-term operation, devices were sealed in air using an epoxy resin and then exposed to continuous illumination for 100 hours (see Experimental Section for details). Note that this procedure is different from typical procedure to estimate the long-term operation of ss-DSSCs, which includes the storage of unsealed devices in an inert atmosphere and occasional measurements of the current-voltage curve in air. We have demonstrated that this method does not reproduce realistic solar cell working conditions and thus does not measure the long-term operating behaviour of ss-DSSCs. ${ }^{15,40}$ In sealed devices, the PCE decreases significantly during the first 100 hours of light exposure mainly as result of a reduction in $J_{\mathrm{sc}}$, while $V_{\mathrm{oc}}$ and FF remain stable. ${ }^{15}$

In Figure 7, $J_{\text {sc }}$ is plotted as a function of the time for the sealed devices employing pyt-COOH, pyt$\mathrm{PO}(\mathrm{OH})_{2}$ and pyt-PO(OEt)OH as sensitizers. Devices with the mono-protected phosphonic acid is significantly more stable compared to cells with the free phosphonic acid and is similar in performance to carboxylic dye containing devices. This is in agreement with Figure 5 showing that pyt- $\mathrm{PO}(\mathrm{OH})_{2}$ in solution bleaches after a few hours, probably due to the strong acidic environment induced by the free phosphonic acid group. This dye was sufficiently stable in ss-DSSCs for a measurement of a few hours, but the devices discoloured during entire period of the ageing test. 


\section{CONCLUSIONS}

We have synthesized of three new $4 H$-pyran-4-ylidene and thiazole derivatives (pyt) as metal-free organic dyes that were successfully employed in ss-DSSCs. The same pyt dye functionalized with carboxylic and phosphonic acid as $\mathrm{TiO}_{2}$ anchoring groups performed similarly in ss-DSSCs, in contrast to reports on liquid electrolyte DSSCs, where dyes employing phosphonic anchoring groups, always exhibited relatively low efficiencies. In particular, the lower fill factor of devices sensitized with phosphonic acid containing dyes was compensated by a higher $V_{\text {occ }}$. A Mott-Schottky analysis and equivalent circuit models demonstrate that phosphonic group induces a significantly increase in built-in voltage at the $\mathrm{TiO}_{2}$-hole transporter interface, which is the cause for this high $V_{\text {oc }}$. pyt- $\mathrm{PO}(\mathrm{OH})_{2}$ sensitized devices exhibited comparable lifetimes as devices employing the $\mathrm{COOH}$-terminated dye. This work therefore demonstrates that $\mathrm{PO}(\mathrm{OH})_{2}$ is a promising anchor group for metal-free organic dyes for use in ss-DSSCs. Our results also reiterate the fact that principles applying to design of highly efficient dyes for liquid electrolyte DSSCs are not always directly applicable to solid-state devices. 


\section{EXPERIMENTAL SECTION}

\section{Synthetic procedures}

Aldehyde 4 was prepared through a two-step synthesis, as shown in Figure 7. The Horner reaction of (2,6diphenyl-4H-pyran-4-yl)diphenylphosphine oxide $\mathbf{1}$ with the available aldehyde $\mathbf{2}$ yielded the intermediate 3, which, by lithiation followed by reaction with anhydrous DMF afforded the desired aldehyde 4 . The organic dye pyt-PO(OEt)OH was obtained with very good yield (98\%) by a Knoevenagel condensation of the aldehyde 4, in presence of piperidine, with diethyl cianomethyl-phosphonate in acetonitrile. The complete deprotection of the phosphonate ester pyt-PO(OEt)OH was successfully achieved with trimethylsilane iodide in $\mathrm{CH}_{2} \mathrm{Cl}_{2}$. Dye pyt-COOH was prepared by a similar Knoevenagel condensation from aldehyde 4 and 2-cyanoacetic acid.<smiles>O=P(c1ccccc1)(c1ccccc1)c1ccccc1</smiles>

1<smiles>CC(C)(C)C1=CC(=Cc2nccs2)C=C(c2ccccc2)O1</smiles>

$85 \%$



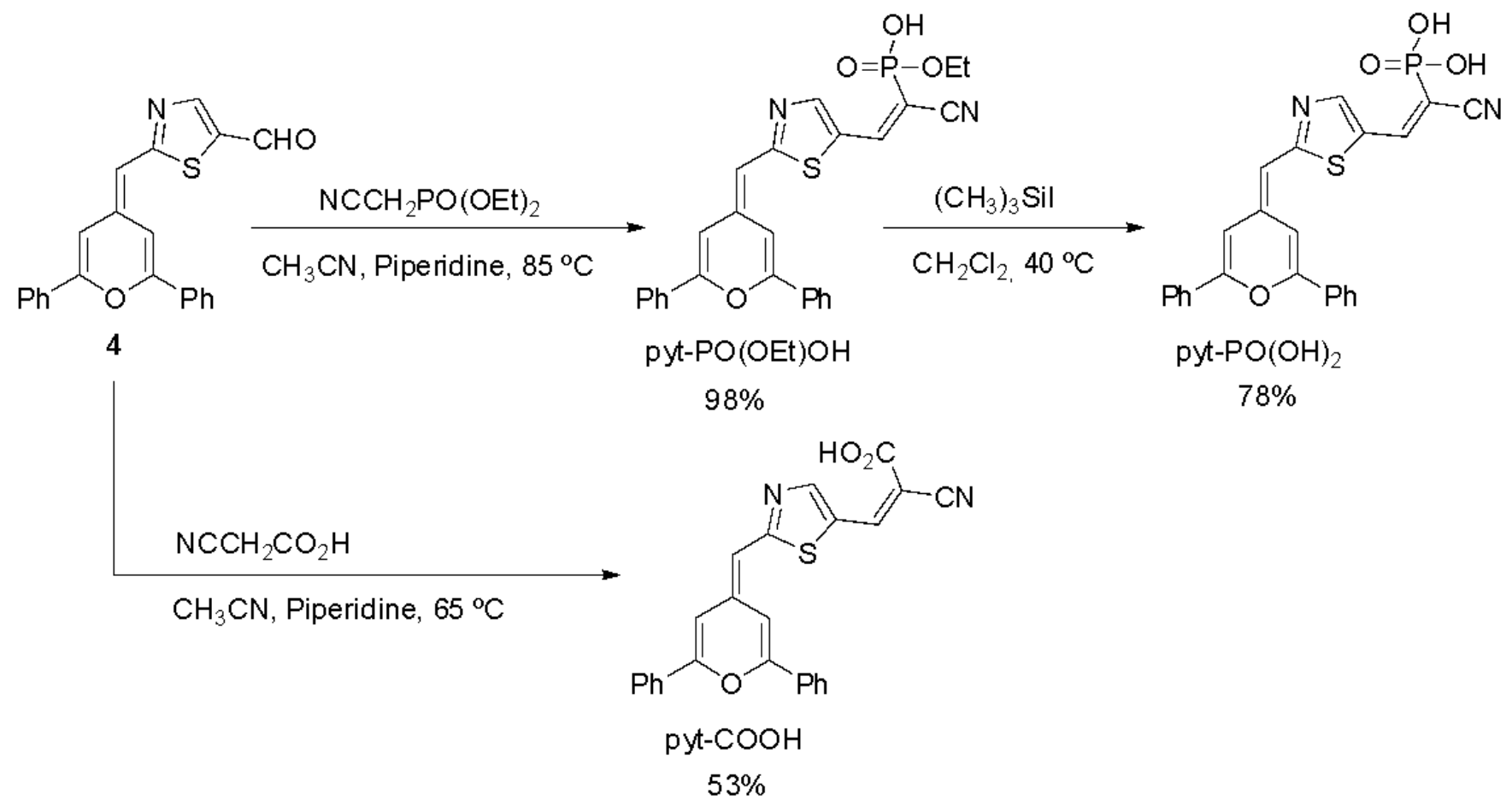

Figure 7. Synthetic procedure scheme for pyt-COOH, pyt-PO(OH $)_{2}$ and pyt-PO(OEt)OH. 
pyt-PO(OEt)OH: Ethyl hydrogen 1-cyano-2-(2-((2,6-diphenyl-4H-pyran-4-ylidene)methyl)thiazol-5yl)vinylphosphonate

Piperidine (307.6 $\mu \mathrm{L}, 2.92 \mathrm{mmol}$ ) was added to a solution of aldehyde 4 (157.3 mg, $0.44 \mathrm{mmol}$ ) and diethyl cyanomethyl-phosphonate $(87.2 \mu \mathrm{l}, 0.53 \mathrm{mmol})$ in $10 \mathrm{~mL}$ of anhydrous acetonitrile. The reaction mixture was heated to reflux for 24 hours under Ar. After removing the solvent the residue was purified by reversed C18 chromatography $\left(\mathrm{CH}_{3} \mathrm{CN} / \mathrm{AcONH}_{4} 20 \mathrm{mM}\right.$ 1/1 as eluent) to give a red solid (210.0 mg, 98\%)

Mp: $241-242{ }^{\circ} \mathrm{C}$.

IR $(\mathrm{KBr}), c m^{-1}: 2197(\mathrm{C} \equiv \mathrm{N}), 1652(\mathrm{P}=\mathrm{O}), 1541(\mathrm{C}=\mathrm{C})$.

${ }^{1}$ H NMR (400 MHz, dmso-d $\left.{ }^{6}\right):{ }^{T M}(p p m) 8.40$ (s, 1H), 8.28 (s, 1H), 7.97-7.87 (m, 4H), 7.83 (d, $J=15.7$ Hz, 1H), 7.65-7.47 (m, 6H), 7.09 (s, 1H), 6.29 (s, 1H), 3.75-3.65 (m, 2H), 1.11 (t, $J=7.0 \mathrm{~Hz}, 3 \mathrm{H})$.

${ }^{13} \mathrm{C}$ NMR (100 MHz, dmso-d $\left.{ }^{6}\right):{ }^{T M}(\mathrm{ppm})$ 169.6, 154.9, 153.2, 151.4, 141.7 (JC-P $\left.=7.0 \mathrm{~Hz}\right), 135.8,131.9$, 131.6, 130.5, 130.1, 129.8, 129.2, 129.0, 125.0, 124.7, $119.1\left(J_{C-P}=8.8 \mathrm{~Hz}\right), 107.9,104.1,104.1,91.2\left(J_{C-}\right.$ $\left.{ }_{P}=133.7 \mathrm{~Hz}\right), 59.6,16.7$.

HRMS $\left(\mathrm{ESI}^{+}\right): \mathrm{m} / \mathrm{z}$ Calcd for $\left[\mathrm{C}_{26} \mathrm{H}_{22} \mathrm{~N}_{2} \mathrm{O}_{4} \mathrm{PS}\right]^{+}:$489.1032, found: 489.1011; $\mathrm{m} / \mathrm{z}$ Calcd for $\left[\mathrm{C}_{26} \mathrm{H}_{21} \mathrm{~N}_{2} \mathrm{NaO}_{4} \mathrm{PS}\right]^{+}$: 511.0852, found: 511.0826.

pyt-PO(OH)2: $\quad$ 1-cyano-2-(2-((2,6-diphenyl-4H-pyran-4-ylidene)methyl)thiazol-5-yl)vinylphosphonic acid

Trimethylsilane iodide ( $185.6 \mu \mathrm{l}, 1.26 \mathrm{mmol}$ ) was added (dropwise) to a solution of pyt-PO(OEt)OH (100 mg, $0.20 \mathrm{mmol}$ ) in $20 \mathrm{ml}$ of $\mathrm{CH}_{2} \mathrm{Cl}_{2}$. After refluxing for $2 \mathrm{~h}$, the mixture was cooled to r.t. and $6 \mathrm{ml}$ of $\mathrm{CH}_{3} \mathrm{OH}$ were added. After stirring for 30 minutes, the solvent was removed and the residue washed with $\mathrm{CH}_{2} \mathrm{Cl}_{2}$ and dried, to give a dark red solid (72.4 mg, 78\%)

Mp: $223-226^{\circ} \mathrm{C}$.

IR (KBr): $\mathrm{cm}^{-1} 2197(\mathrm{C} \equiv \mathrm{N}), 1646(\mathrm{P}=\mathrm{O}), 1540(\mathrm{C}=\mathrm{C})$.

${ }^{1}$ H NMR (400 MHz, dmso-d $\left.{ }^{6}\right):{ }^{T M}(\mathrm{ppm}) 8.49$ (s, 1H), 8.44 (d, $\left.J=1.1 \mathrm{~Hz}, 1 \mathrm{H}\right), 8.07$ (d, $\left.J=18.2 \mathrm{~Hz}, 1 \mathrm{H}\right)$, 7.99-7.87 (m, 2H), 7.64-7.51 (m, 6H), 7.13 (d, $J=1.2 \mathrm{~Hz}, 1 \mathrm{H}), 6.35$ (s, 1H).

${ }^{13}$ C NMR (100 MHz, dmso-d $\left.{ }^{6}\right):{ }^{T M}(p p m) ~ 171.6,155.5,154.3,153.9,144.6\left(J_{C-P}=6.6 \mathrm{~Hz}\right), 137.3,131.8$, 131.5, 130.7, 130.4, 129.3, 129.1, $128.5\left(J_{C-P}=18.2 \mathrm{~Hz}\right), 125.2,124.9,117.4\left(J_{C-P}=10.1 \mathrm{~Hz}\right), 108.1,104.4$, 104.0, $100.6\left(J_{C-P}=187.0 \mathrm{~Hz}\right)$.

HRMS (ESI ${ }^{+}$): $\mathrm{m} / \mathrm{z}$ Calcd for $\left[\mathrm{C}_{24} \mathrm{H}_{18} \mathrm{~N}_{2} \mathrm{O}_{4} \mathrm{PS}\right]^{+}:$461.0719, found: 461.0705 . 
pyt-COOH: 2-cyano-3-(2-((2,6-diphenyl-4H-pyran-4-ylidene)methyl)thiazol-5-yl)acrylic acid

Piperidine (222 $\mu \mathrm{l} ; 2.22 \mathrm{mmol})$ was added to a solution of aldehyde 4 (120 mg; $0.33 \mathrm{mmol}$ ) and 2cyanoacetic acid (44.5 mg; $0.52 \mathrm{mmol}$ ) in $10 \mathrm{ml}$ chloroform. The reaction mixture was heated to reflux for 3 days and 19 hours under Ar. After removing the solvent the residue was purified by reversed C18 chromatography $\left(\mathrm{CH}_{3} \mathrm{CN} / \mathrm{AcONH}_{4} 20 \mathrm{mM}\right.$ 1/1 as eluent) to give a dark red solid (75.5 mg, 53\%)

Mp: $263-265^{\circ} \mathrm{C}$.

IR (KBr): $\mathrm{cm}^{-1} 2213(\mathrm{C} \equiv \mathrm{N}), 1649(\mathrm{C}=\mathrm{O}), 1545(\mathrm{C}=\mathrm{C})$.

${ }^{1}$ H NMR (400 MHz, dmso-d ${ }^{6}$ ): ${ }^{T M}$ (ppm) 8.57 (s, 1H), 8.49 (s, 1H), 8.45 (d, $\left.J=1.4 \mathrm{~Hz}, 1 \mathrm{H}\right), 7.95-7.89$ (m, 4H), 7.61-7.52 (m, 6H), 7.15 (d, $J=1.4 \mathrm{~Hz}, 1 \mathrm{H}), 6.37$ (s, 1H).

${ }^{13}$ C NMR (100 MHz, dmso-d ${ }^{6}$ ): TM (ppm) 173.3, 163.4, 156.5, 155.9, 154.4, 144.3, 138.3, 131.6, 131.4, 130.5, 130.2, 129.0, 128.9, 127.0, 125.1, 124.8, 116.4, 108.2, 104.5, 104.1, 97.6.

HRMS (ESI ${ }^{+}$): $m / z$ Calcd for $\left[\mathrm{C}_{25} \mathrm{H}_{17} \mathrm{~N}_{2} \mathrm{O}_{3} \mathrm{~S}\right]^{+}:$425.0954, found: 425.0954. Calcd for $\left[\mathrm{C}_{25} \mathrm{H}_{16} \mathrm{~N}_{2} \mathrm{O}_{3} \mathrm{SNa}\right]^{+}$: 447.0774, found: 447.0776 .

\section{Methods.}

Chemical characterization. Melting point (Mp) was recorded using a Gallenkamp apparatus. Fourier transform infrared spectrum (IR) was recorded in $\mathrm{KBr}$ pellets using a Perkin-Elmer $1600 .{ }^{1} \mathrm{H}$ and ${ }^{13} \mathrm{C}$ NMR spectra were recorded on a Bruker AV400 spectrometer (400 MHz for ${ }^{1} \mathrm{H}$ and $100 \mathrm{MHz}$ for ${ }^{13} \mathrm{C}$ ). The deuterated solvents are indicated; chemical shifts $(\delta)$ are given in ppm, using the solvent residual signal as an internal standard $\left({ }^{1} \mathrm{H},{ }^{13} \mathrm{C}\right)$. Electrospray (ESI) mass spectra were recorded on a Bruker microTOF-Q spectrometer, accurate mass measurements (HRMS) were achieved using sodium formiate as external reference.

Electrochemical characterization. The electrochemical properties of the dyes were studied by using differential pulse voltammetry (DPV) with a step potential of $5 \mathrm{mV}$, square wave amplitude of $25 \mathrm{mV}$, and a scan rate of $50 \mathrm{mV} / \mathrm{s}$. Measurements were performed under argon, in anhydrous DMF (10 ${ }^{-3} \mathrm{M}$ solution) using $0.1 \mathrm{M}$ tetrabutylammonium hexafluorophosphate $\left(\mathrm{TBAPF}_{6}\right)$ as the supporting electrolyte, a glassy carbon working electrode (3 mm diameter), a Pt counter electrode and a Ag/AgCl reference electrode. All 
measurements were made at room temperature using a $\mu$ AUTOLAB Type III potentiostat, driven by the electrochemical software NOVA v10.1.

Optical characterization. Solution UV-Visible absorption spectra were recorded using a UNICAM UV4 UV/Vis/NIR spectrophotometer. All samples were measured in a $1 \mathrm{~cm}$ cell at room temperature with anhydrous DMF as solvent. Concentration of $10^{-5} \mathrm{M}$ was used for solution UV-Visible. In order to assure that the dyes were completely protonated, we added several drops of $\mathrm{HCl}(1 \mathrm{~N})$ to the DMF solution.

Computational details. Theoretical calculations were performed using Gaussian $09^{51}$ and the default parameters provided by this software package. Solvent effects were estimated using a Conductor-like Polarizable Continuum Model (CPCM). ${ }^{52,53}$ Equilibrium geometries in solution were obtained using the M06-2x hybrid meta-GGA exchange-correlation functional ${ }^{54}$ and the medium size $6-31 G^{*}$ basis set $^{55}$ both $^{\text {th }}$ for ground and first excited states. Excitation energies were calculated by time-dependent single point calculations using the M06-2x/6-311+G(2d,p) model chemistry. Vertical excitation energies were calculated at the optimized ground state geometry, while adiabatic excitation energies (E0-0) were calculated by subtracting the ground state energy from the excited state energy both calculated at their optimized geometry. Molecular Orbital contour plots were obtained using the Avogadro software ${ }^{56}$ at 0.04 isosurface value.

Solar cell fabrication. The ss-DSSCs were prepared with a procedure similar to what we previously reported. $^{32}$ All solvents used for device fabrication were reagent grade and anhydrous. FTO substrates (15 $\Omega /$ sq, Pilkington) were etched with zinc powder and $\mathrm{HCl}$ (2 $\mathrm{M}$ aqueous solution) to give the desired electrode patterning. The substrates were cleaned with Hellmanex ( $2 \%$ by volume in water), de-ionized water, acetone, and ethanol. The residual traces of organics were removed by a 10 minute oxygen plasma cleaning step. The FTO sheets were subsequently coated with a compact layer of $\mathrm{TiO}_{2}(70 \mathrm{~nm})$ by aerosol spray pyrolysis deposition at $270^{\circ} \mathrm{C}$, using oxygen as the carrier gas. Films of $1.5 \mu \mathrm{m}$ thick mesoporous $\mathrm{TiO}_{2}$ were then deposited by screen-printing a commercial paste (Dyesol 18NR-T) diluted in terpineol to obtain the desired thickness. The $\mathrm{TiO}_{2}$ films were slowly heated to $500{ }^{\circ} \mathrm{C}$ and allowed to sinter for $30 \mathrm{~min}$ in air. Once cooled, the samples were immersed into a $15 \mathrm{mM} \mathrm{TiCl}_{4}$ aqueous solution for $45 \mathrm{~min}$ at $70^{\circ} \mathrm{C}$ and then heated to $500^{\circ} \mathrm{C}$ for another sintering step of $45 \mathrm{~min}$. After cooling to $70^{\circ} \mathrm{C}$, the substrates were immersed in about $0.1 \mathrm{mM}$ solution of dye in 1:1 mixture of acetonitrile and tert-butyl alcohol for 3 hours. After the dyed films were rinsed in abundant acetonitrile, then the hole conductor matrix was applied by spin-coating at $1000 \mathrm{rpm}$ for $45 \mathrm{~s}$ in air. The solutions for spin coating consisted of $80 \mathrm{mM}$ of 2,2'-7,7'tetrakis(N,N-di-p-methoxyphenylamine)-9,9'-spirobifluorene (spiro-OMeTAD), $15 \mathrm{mM}$ of lithium 
bis(trifluoromethylsulfonyl)imide salt (Li-TFSI) and $70 \mathrm{mM}$ of 4-tert-butylpyridine (tBP) in anhydrous chlorobenzene. After drying overnight, $150 \mathrm{~nm}$ of silver back contacts were applied by thermal evaporation in high vacuum.

Solar cells performance. ${ }^{57}$ For measuring the device merit parameters, simulated AM 1.5 sunlight was generated with a class AAB ABET solar simulator calibrated to give simulated AM 1.5, $100 \mathrm{mWcm}^{-2}$ irradiance, using an NREL-calibrated KG5 filtered silicon reference cell, with less than 1\% mismatch factor; the current-voltage curves were recorded with a sourcemeter (Keithley 2400, USA). The solar cells were masked with a metal aperture defining the active area $\left(0.065 \mathrm{~cm}^{2}\right)$ of the solar cells. All devices were stored in air and in dark for 24 hours prior to testing.

Photovoltaic action spectra were measured (2400 Series SourceMeter, Keithley Instruments) with chopped monochromatic light incident which were biased with white light-emitting diodes (LED) at an equivalent solar irradiance of $10 \mathrm{~mW} \mathrm{~cm}^{-2}$. The monochromatic light intensity for the incident photon-to-electron conversion efficiency (EQE) was calibrated with a UV-enhanced silicon photodiode. The solar cells were masked with a metal aperture to define the active area which was typically $0.065 \mathrm{~cm}^{2}$ and measured in a light-tight sample holder to minimize any edge effects.

Capacitance-voltage measurements were taken using FRA-equipped PGSTAT-302N from Autolab, 20 mV AC sinusoidal signal with the frequency ranging from $1 \mathrm{MHz}$ to $0.1 \mathrm{~Hz}$ for each voltage bias (forward bias ranging from $0 \mathrm{~V}$ to $1.2 \mathrm{~V}$ ). $\mathrm{TiO}_{2}$ films were prepared with the same procedure we used to prepare the solar cells. The $\mathrm{TiO}_{2}$ surface was modified with benzoic and phenylphosphonic acids following the same procedure used for dye sensitization.

Long-term stability was performed by sealing the devices in air with epoxy resin and leaving them at open circuit condition under $\mathrm{AM} 1.5,100 \mathrm{~mW} \mathrm{~cm}^{-2}$ simulated sun light at $40^{\circ} \mathrm{C}$, filtering the $\mathrm{UV}$ light. For measuring the device performance current-voltage curves under simulated full sun light were collected as described in the previous paragraphs. 


\section{ACKNOWLEDGEMENT}

AA has received funding from the European Union's Seventh Framework Programme for research, technological development and demonstration under grant agreement no 291771. We gratefully acknowledge the financial support from the Spanish Ministry of Science and Innovation, MICINN-FEDER (project CTQ2011-22727) and the Gobierno de Aragón-Fondo Social Europeo (E39). A predoctoral fellowship to RPT (CSIC, JAE 2011) is also acknowledged.

\section{SUPPORTING INFORMATION}

Computational details; NMR spectra; absorption and emission spectra in ${ }^{t} \mathrm{BuOH}: \mathrm{CH}_{3} \mathrm{CN}$ (1:1); electrochemical characterisation; relative dye concentration on the $\mathrm{TiO}_{2}$ surface; dye solution calibration curves; device performance parameters collected over 6 months of experiments. 


\section{REFERENCES}

(1) Aslani, A.; Wong, K.-F. V. Renewable Energy 2014, 63, 153.

(2) Milbrandt, A. R.; Heimiller, D. M.; Perry, A. D.; Field, C. B. Renewable and Sustainable Energy Reviews 2014, 29, 473.

(3) Batas Bjelic, I.; Ciric, R. M. Renewable and Sustainable Energy Reviews 2014, 39, 79.

(4) Chen, S. F.; Lin, F. T.; Zhao, S.; Bai, J. F.; Tong, R. M. Advanced Materials Research 2014, 834, 1110.

(5) Lee, M. M.; Teuscher, J.; Miyasaka, T.; Murakami, T. N.; Snaith, H. J. Science 2012, 338,

643.

(6) Cannavale, A.; Manca, M.; Malara, F.; De Marco, L.; Cingolani, R.; Gigli, G. Energy \& Environmental Science 2011, 4, 2567.

(7) Eperon, G. E.; Burlakov, V. M.; Goriely, A.; Snaith, H. J. ACS nano 2014, 8, 591.

(8) Fakharuddin, A.; Jose, R.; Brown, T. M.; Fabregat-Santiago, F.; Bisquert, J. Energy \& Environmental Science 2014, 7, 3952.

(9) Zhao, L.; Wagner, P.; Elliott, A. B.; Griffith, M. J.; Clarke, T. M.; Gordon, K. C.; Mori, S.; Mozer, A. J. Journal of Materials Chemistry A 2014, 2, 16963.

(10) Wang, S.-W.; Chou, C.-C.; Hu, F.-C.; Wu, K.-L.; Chi, Y.; Clifford, J. N.; Palomares, E.; Liu, S.-H.; Chou, P.-T.; Wei, T.-C. Journal of Materials Chemistry A 2014, 2, 17618.

A 2014.

(11) Cho, W.; Kim, Y. R.; Song, D.; Choi, H. W.; Kang, Y. S. Journal of Materials Chemistry

(12) O’Rdgan, B.; Gratzel, M. Nature 1991, 353, 737.

(13) Abate, A.; Petrozza, A.; Roiati, V.; Guarnera, S.; Snaith, H.; Matteucci, F.; Lanzani, G.; Metrangolo, P.; Resnati, G. Organic Electronics 2012, 13, 2474.

(14) Abate, A.; Petrozza, A.; Cavallo, G.; Lanzani, G.; Matteucci, F.; Bruce, D. W.; Houbenov, N.; Metrangolo, P.; Resnati, G. Journal of Materials Chemistry A 2013, 1, 6572.

(15) Pathak, S. K.; Abate, A.; Leijtens, T.; Hollman, D. J.; Teuscher, J.; Pazos, L.; Docampo, P.; Steiner, U.; Snaith, H. J. Advanced Energy Materials 2014, 4, 1301667. 1300489.

(16) Park, S. H.; Lim, J.; Song, I. Y.; Lee, J. R.; Park, T. Advanced Energy Materials 2014, 4,

(17) Ooyama, Y.; Sato, T.; Harima, Y.; Ohshita, J. Journal of Materials Chemistry A 2014, 2, 3293.

(18) Giannopoulos, P.; Nikolakopoulou, A.; Andreopoulou, A. K.; Sygellou, L.; Kallitsis, J. K.; Lianos, P. Journal of Materials Chemistry A 2014, 2, 20748.

(19) Wang, L.; Yang, X.; Wang, X.; Sun, L. Dyes and Pigments 2015, 113, 581.

(20) Zhang, L.; Cole, J. M. ACS applied materials \& interfaces 2015, 7, 3427.

(21) Brennan, B. J.; Portolés, M. J. L.; Liddell, P. A.; Moore, T. A.; Moore, A. L.; Gust, D. Phys. Chem. Chem. Phys. 2013, 15, 16605.

(22) Pujari, S. P.; Scheres, L.; Marcelis, A.; Zuilhof, H. Angewandte Chemie International Edition 2014, 53, 6322.

(23) Brown, D. G.; Schauer, P. A.; Borau-Garcia, J.; Fancy, B. R.; Berlinguette, C. P. Journal of the American Chemical Society 2013, 135, 1692.

(24) Nilsing, M.; Lunell, S.; Persson, P.; Ojamäe, L. Surface science 2005, 582, 49.

(25) Nilsing, M.; Persson, P.; Ojamäe, L. Chemical physics letters 2005, 415, 375.

(26) Luschtinetz, R.; Frenzel, J.; Milek, T.; Seifert, G. The Journal of Physical Chemistry C 2009, 113, 5730 .

(27) Luschtinetz, R.; Gemming, S.; Seifert, G. The European Physical Journal Plus 2011, 126, 1. 
(28) Wang, P.; Klein, C.; Moser, J.-E.; Humphry-Baker, R.; Cevey-Ha, N.-L.; Charvet, R.; Comte, P.; Zakeeruddin, S. M.; Grätzel, M. The Journal of Physical Chemistry B 2004, 108, 17553.

(29) Murakami, T. N.; Yoshida, E.; Koumura, N. Electrochimica Acta 2014, 131, 174.

(30) Neuthe, K.; Bittner, F.; Stiemke, F.; Ziem, B.; Du, J.; Zellner, M.; Wark, M.; Schubert, T.; Haag, R. Dyes and Pigments 2014, 104, 24.

(31) Malzner, F. J.; Brauchli, S. Y.; Schönhofer, E.; Constable, E. C.; Housecroft, C. E. Polyhedron 2014, 82, 116.

(32) Abate, A.; Planells, M.; Hollman, D. J.; Stranks, S. D.; Petrozza, A.; Kandada, A. R. S.; Vaynzof, Y.; Pathak, S. K.; Robertson, N.; Snaith, H. J. Advanced Energy Materials 2014, 4, 1400166.

(33) Dessì, A.; Calamante, M.; Mordini, A.; Peruzzini, M.; Sinicropi, A.; Basosi, R.; de Biani, F. F.; Taddei, M.; Colonna, D.; Di Carlo, A. Chemical Communications 2014, 50, 13952.

(34) Bach, U.; Lupo, D.; Comte, P.; Moser, J.; Weissörtel, F.; Salbeck, J.; Spreitzer, H.; Grätzel, M. Nature 1998, 395, 583.

(35) Abate, A.; Leijtens, T.; Pathak, S.; Teuscher, J.; Avolio, R.; Errico, M. E.; Kirkpatrik, J.; Ball, J. M.; Docampo, P.; McPherson, I. Physical Chemistry Chemical Physics 2013, 15, 2572.

(36) Marotta, G.; Lobello, M. G.; Anselmi, C.; Barozzino Consiglio, G.; Calamante, M.; Mordini, A.; Pastore, M.; De Angelis, F. ChemPhysChem 2014, 15, 1116.

(37) Matsuzaki, H.; Murakami, T. N.; Masaki, N.; Furube, A.; Kimura, M.; Mori, S. The Journal of Physical Chemistry C 2014, 118, 17205.

48, 2474.

(38) Mishra, A.; Fischer, M. K.; Bäuerle, P. Angewandte Chemie International Edition 2009,

(39) Abate, A.; Hollman, D. J.; Teuscher, J.; Pathak, S.; Avolio, R.; D’Errico, G.; Vitiello, G.; Fantacci, S.; Snaith, H. J. Journal of the american chemical society 2013, 135, 13538.

(40) Pathak, S. K.; Abate, A.; Ruckdeschel, P.; Roose, B.; Gödel, K. C.; Vaynzof, Y.; Santhala, A.; Watanabe, S. I.; Hollman, D. J.; Noel, N. Advanced Functional Materials 2014, 24, 6046.

(41) Janotti, A.; Varley, J.; Rinke, P.; Umezawa, N.; Kresse, G.; Van de Walle, C. Physical Review B 2010, 81, 085212.

(42) Leijtens, T.; Eperon, G. E.; Pathak, S.; Abate, A.; Lee, M. M.; Snaith, H. J. Nature communications 2013, 4.

(43) Sivaram, V.; Crossland, E. J.; Leijtens, T.; Noel, N. K.; Alexander-Webber, J.; Docampo, P.; Snaith, H. J. The Journal of Physical Chemistry C 2014, 118, 1821.

(44) Kong, M.; Li, Y.; Chen, X.; Tian, T.; Fang, P.; Zheng, F.; Zhao, X. Journal of the American Chemical Society 2011, 133, 16414.

(45) Kirchartz, T.; Gong, W.; Hawks, S. A.; Agostinelli, T.; MacKenzie, R. C.; Yang, Y.;

Nelson, J. The Journal of Physical Chemistry C 2012, 116, 7672.

(46) Foster, J.; Kirkpatrick, J.; Richardson, G. Journal of applied physics 2013, 114, 104501.

(47) Han, L.; Koide, N.; Chiba, Y.; Islam, A.; Komiya, R.; Fuke, N.; Fukui, A.; Yamanaka, R. Applied Physics Letters 2005, 86, 213501.

(48) Koide, N.; Islam, A.; Chiba, Y.; Han, L. Journal of Photochemistry and Photobiology A: Chemistry 2006, 182, 296.

(49) Schenk, A.; Krumbein, U. Journal of applied physics 1995, 78, 3185.

(50) Kirkpatrick, J.; Keivanidis, P. E.; Bruno, A.; Ma, F.; Haque, S. A.; Yarstev, A.;

Sundstrom, V.; Nelson, J. The Journal of Physical Chemistry B 2011, 115, 15174.

(51) Frisch, M.; Trucks, G.; Schlegel, H.; Scuseria, G.; Robb, M.; Cheeseman, J.; Scalmani, G.; Barone, V.; Mennucci, B.; Petersson, G. Inc., Wallingford, CT 2009.

(52) Barone, V.; Cossi, M. The Journal of Physical Chemistry A 1998, 102, 1995.

(53) Cossi, M.; Rega, N.; Scalmani, G.; Barone, V. Journal of computational chemistry 2003, 24, 669.

(54) Zhao, Y.; Truhlar, D. G. Theoretical Chemistry Accounts 2008, 120, 215.

(55) Hariharan, P.; Pople, J. A. Molecular Physics 1974, 27, 209. 
(56) Hanwell, M. D.; Curtis, D. E.; Lonie, D. C.; Vandermeersch, T.; Zurek, E.; Hutchison, G. R. J. Cheminformatics 2012, 4, 17.

(57) Snaith, H. J. Energy \& Environmental Science 2012, 5, 6513. 